This document is confidential and is proprietary to the American Chemical Society and its authors. Do not copy or disclose without written permission. If you have received this item in error, notify the sender and delete all copies.

\title{
Sequence Independent Cloning and Post-translational Modification of Repetitive Protein Polymers through Sortase and Sfp-mediated Enzymatic Ligation
}

\begin{tabular}{|r|l|}
\hline Journal: & Biomacromolecules \\
\hline Manuscript ID & bm-2015-01726r.R1 \\
\hline Danuscript Type: & Article \\
\hline Complete List of Authors: & $\begin{array}{l}\text { Ott, Wolfgang; Ludwig-Maximilians-Universitat Munchen } \\
\text { Nicolaus, Thomas; Ludwig-Maximilians-Universitat Munchen } \\
\text { Gaub, Hermann; LMU, } \\
\text { Nash, Michael; Ludwig-Maximilians-University of Munich, Physik }\end{array}$ \\
\hline
\end{tabular}

SCHOLARONE ${ }^{m}$

Manuscripts 
1

2

3

4

5

$6{ }^{\dagger}$ Lehrstuhl für Angewandte Physik, Ludwig-Maximilians-Universität München, 80799 Munich,

7 Germany.

8 Center for Nanoscience (CeNS), Ludwig-Maximilians-Universität München, 80799 Munich,

9 Germany.

$10 \S$ Center for Integrated Protein Science Munich (CIPSM), Ludwig-Maximilians-Universität

11 München, 81377 Munich, Germany.

$12{ }^{\perp}$ Department of Chemistry, University of Basel, 4056 Basel, Switzerland.

13 Department of Biosystems Science and Engineering, Eidgenössische Technische Hochschule 14 (ETH-Zürich), 4058 Basel, Switzerland.

15

16 Keywords: Golden Gate assembly, elastin-like polypeptides, sequence independent cloning,

17 post-translational protein ligation, bioconjugation

\section{Sequence Independent Cloning and Post-}

\section{Enzymatic Ligation}


19 Repetitive protein-based polymers are important for many applications in biotechnology and

20 biomaterials development. Here we describe the sequential additive ligation of highly repetitive

21 DNA sequences, their assembly into genes encoding protein-polymers with precisely tunable

22 lengths and compositions, and their end-specific post-translational modification with organic

23 dyes and fluorescent protein domains. Our new Golden Gate-based cloning approach relies on

24 incorporation of only type IIS BsaI restriction enzyme recognition sites using PCR, which

25 allowed us to install ybbR-peptide tags, Sortase c-tags, and cysteine residues onto either end of

26 the repetitive gene polymers without leaving any cloning scars. The assembled genes were

27 expressed in Escherichia coli and purified using inverse transition cycling (ITC).

28 Characterization by cloud point spectrophotometry, and denaturing polyacrylamide gel

29 electrophoresis with fluorescence detection confirmed successful phosphopantetheinyl

30 transferase (Sfp)-mediated post-translational N-terminal labeling of the protein-polymers with a

31 Coenzyme A-647 dye (CoA-647), and simultaneous Sortase-mediated C-terminal labeling with a

32 GFP domain containing an N-terminal GG-motif in a one pot reaction. In a further

33 demonstration, we installed an N-terminal cysteine residue into a 60 pentapeptide ELP that was

34 subsequently conjugated to a single chain poly(ethylene glycol)-maleimide (PEG-maleimide)

35 synthetic polymer, noticibly shifting the ELP cloud point. The ability to straightforwardly

36 assemble repetitive DNA sequences encoding ELPs of precisely tunable length, and to post-

37 translationally modify them specifically at the $\mathrm{N}$ - and $\mathrm{C}$ - termini provides a versatile platform for

38 the design and production of multi-functional smart protein-polymeric materials.

40 INTRODUCTION 
41 Repetitive polymers of controlled length and tunable phase-transition behavior are urgently 42 needed for a variety of applications in the nano/biosciences, including drug delivery ${ }^{1,2}$, and 43 medical diagnostics ${ }^{3}$. Such stimuli-responsive polymeric materials are of high interest for 44 fundamental investigations into biomolecules under the influence of mechanical, thermal, and 45 chemical denaturants using biophysical methods such as single-molecule AFM force 46 spectroscopy $^{4,5}$ and microscale thermophoresis ${ }^{6}$. Elastin like polypeptides (ELPs) are artificial 47 proteins derived from naturally occurring elastomeric proteins ${ }^{7,8}$. Recombinant ELPs consist of 48 repeats of the amino acid sequence Val-Pro-Gly-Xaa-Gly, where Xaa represents any amino acid 49 except proline. ELPs exhibit a reversible lower critical solution temperature (LCST), and 50 undergo a phase transition that can be triggered by temperature ${ }^{9}$. Other environmental stimuli 51 like $\mathrm{pH}$ or ionic strength can also be used to collapse ELPs under isothermal conditions. The 52 guest residue (Xaa) can be used to influence the $\mathrm{pH} /$ thermal phase transition properties of the 53 resulting protein-polymers. Insertion of acidic residues such as glutamate or aspartate in the 54 guest residue position results in $\mathrm{pH}$-responsive behavior. The transition temperature is strongly 55 dependent on the concentration and molecular weight, with longer ELP sequences collapsing at 56 lower temperatures. One can also tune the cloud point by changing several environmental 57 parameters at once (e.g., temperature, $\mathrm{pH}$, salt), thereby shifting the transition to lower or higher 58 temperatures as desired $^{10}$.

60 These unique properties of ELPs make them attractive for a variety of applications and scientific 61 investigations ${ }^{11}$. Chromatography free protein purification, for example, can be performed by 62 producing a target protein as an ELP fusion, and precipitating it from cellular extracts, avoiding 63 the need for affinity tags. This method allows for purification of recombinant proteins under mild 
64 conditions. Moreover, it is reported that in combination with maltose binding proteins, ELPs can

65 improve the solubility of fusion domains and thereby improve expression yields ${ }^{12-14}$.

67 In the field of biomaterials science, ELPs represent a viable option as a scaffold material for

68 tissue engineering, or as carriers for drug molecules. Applications for in vivo systems demand

69 high predictability and controllability of the biophysical behavior of the molecules. Since ELPs

70 consist only of amino acids, they are competitive in terms of biocompatibility and biodegradation

71 in vivo as compared to their synthetic organic polymer counterparts ${ }^{15,16}$. ELPs possess the added

72 advantage of complete monodispersity. More fundamentally, the phase transition characteristics

73 of ELPs have served as an ideal model system for theoretical calculations and modeling

74 studies $^{17-21}$. Additionally, conjugates between ELPs and synthetic polymers (e.g., PEG) are of 75 high interest, and would benefit from site-specific conjugation approaches ${ }^{22,23}$.

77 In order to fully leverage the versatility of repetitive protein-polymers such as ELPs, modular

78 and straightforward approaches to cloning and site-specific post-translational modification are

79 highly desirable. Standard solid-phase gene synthesis methods are so far not able to produce the

80 long ( $>600 \mathrm{bp}$ ) strands of repetitive DNA required for encoding thermally responsive elastin-like 81 polypeptides (ELPs) with lengths $>200$ amino acids. Typically rationally designed ELPs are 82 constructed using recursive directional ligation (RDL), which requires plasmid amplification, 83 and restriction digestion, and imposes certain restrictions (i.e., the absence of restriction sites) ${ }^{24}$. 84 Larger ELP genes can also be obtained with the OERCA (overlap extension rolling circle 85 amplification) method, which generates a distribution of unspecified lengths of repetitive DNA 86 sequences $^{25}$. 
88 Compared to the RDL method our Golden Gate approach presented here avoids cloning scars

89 due to the use of type IIS restriction enzymes, and is able to cut scarlessly within the coding 90 region ${ }^{24,26}$. The PRe-RDL (RDL by plasmid reconstruction) method relies on several type IIS 91 restriction enzymes and requires certain modifications of the backbone beforehand ${ }^{27}$.

93 Our method is applicable to a broad spectrum of plasmids, since the only limitation is one type

94 IIS restriction enzyme with a recognition site not present in the backbone. Along with this 95 advantage, it is likewise ideal for adding ELPs to an existing gene-containing plasmid to create 96 fusion proteins with different length ELPs. The combinational possibilities also do not rely on a 97 plasmid library, but can be designed using a bottom up block assembly approach. Our approach 98 can also be used in a complimentary way with the existing RDL and OERCA methods, for 99 example, by easily generating fast and reliable plasmid libraries which can then be further 100 extended by combining with RDL or OERCA methods.

101

102 We present a sequence independent approach based on the Golden Gate technology employing 103 polymerase chain reaction (PCR) amplification of short ELP repeats and ligation into a plasmid 104 backbone to produce repetitive ELP genes with specific peptide tag end groups for covalent post105 translational modification. A single type IIS restriction enzyme is used to create unique ends and 106 guarantee the order of DNA block assembly. Using this method, repetitive DNA sequences up to 107 hundreds of $\mathrm{nm}$ in length (i.e., 120 pentapeptide repeats of ELPs) can be rationally designed and 108 created. 5' and 3' tags for post-translational modifications were readily incorporated during the 109 cloning workflow, providing many further possibilities for downstream conjugation and labeling. 
110 Due to the modularity of the system, we were also able to readily install peptide tags (i.e., $\mathrm{ybbR}^{28}$ 111 and Sortase sequences) to the ELP, enabling enzyme-catalyzed ligation of the peptides to

112 fluorescent proteins and organic dyes (as shown below). Our approach builds on the prior 113 method shown by Huber et al. which demonstrated fusion of different kinds of repetitive DNA to 114 create chimeras of ELPs, silk peptides and similar proteins ${ }^{29}$. Our methodology is also 115 compatible with their approach with the advantage of using only one type IIS restriction enzyme. 116

117 Alternatively, it is possible to modify the carrier plasmid in the first amplification round and add 118 ELP flanking tags or protein domains easily. Since the reaction starts new every three fragments, 119 one can easily define block patterns that build up an overall sequence. For example, $\mathrm{pH}$ 120 responsive blocks can be interspersed with $\mathrm{pH}$-insensitive blocks. In regards to user-friendliness, 121 the presented method is advantageous because it relies on the same ELP gene inserts, which can 122 be reused. Once successful amplification and purification of the sequences is achieved, the PCR 123 amplicons can be stored and used again as needed. This way it is possible to create a whole 124 library of gene sequences and, if desired shuffle these each ligation cycle. Post-translational 125 fusion of ELPs using Sortase ligation circumvents the known issue of low protein yields for N126 terminally located ELP domains in fusion proteins ${ }^{30,31}$. Instead of optimizing expression 127 conditions for proteins of low yield, a protein of interest can be produced in its native state and 128 fused afterwards post-translationally with the ELP domain. To the best of our knowledge, this 129 represents the first report using a Sortase-based recognition sequence to fuse ELP proteins to 130 other proteins ${ }^{13,32}$. 


\section{MATERIALS AND METHODS}

132 All used reagents were of analytical purity grade and were purchased from Sigma-Aldrich (St.

133 Louis, MO, USA) or Carl Roth GmbH (Karlsruhe, Germany).

135 Monomer Gene Synthesis. A synthetic gene encoding 150 nucleotides (10 pentapeptide repeats)

136 for the (VPGVG) $)_{5}-(\mathrm{VPGAG})_{2}-(\mathrm{VPGGG})_{3}$ peptide (Centic Biotech, Heidelberg, Germany) served

137 as starting material (see Supporting Information, DNA Sequence 1 and Protein Sequence 1).

139 Cloning. Golden Gate cloning was employed to create the different rationally designed ELP 140 constructs $^{26}$. PCR (Backbone: $98^{\circ} \mathrm{C} 2 \mathrm{~min},\left(98^{\circ} \mathrm{C} 7 \mathrm{~s}, 72^{\circ} \mathrm{C} 2 \mathrm{~min} 30 \mathrm{~s}\right) \times 30,72^{\circ} \mathrm{C} 5 \mathrm{~min}$; Insert: $\left.14198^{\circ} \mathrm{C} 2 \mathrm{~min}, 98^{\circ} \mathrm{C} 7 \mathrm{~s}, 60^{\circ} \mathrm{C} 7 \mathrm{~s}, 72^{\circ} \mathrm{C} 5 \mathrm{~s}\right) \times 30,72^{\circ} \mathrm{C} 5 \mathrm{~min}$ ) was performed with a Phusion high

142 fidelity polymerase master mix. A typical $20 \mu 1$ PCR mix contained $10 \mu$ Phusion high fidelity 143 polymerase master mix (Thermo Fisher Scientific Inc., Waltham, MA, USA), $0.5 \mu 1$ per forward 144 and reverse primer $(10 \mu \mathrm{M}), 1.5 \mu 1 \mathrm{DMSO}, 1 \mathrm{ng}$ of template and water. All primers (biomers.net, 145 Ulm, Germany) used in this study are listed in Tab. 1.

146 Table 1. Overview of employed primers
Primer Sequence 5' -3 '
(1b) REV ELP I
GGTCTCCTCCTTCACCCGGAACGCCACCCCCCGGAACACC GCCGC $\begin{array}{ll}\text { (1a) FW ELP I ybbR } & \text { TATATAGGTCTCCTGGCTGTGCCGGGAGAAGGAGTCCCTGG } \\ \text { TGTCGGTGTCCCAGGCG }\end{array}$
(2a) FW ELP II
TATATAGGTCTCAAGGAGTACCAGGCGAAGGCGTGCCGG GTGTC
(2b) REV ELP II
ATATATGGTCTCACCCTCACCCGGAACGCCACCCCCCGGA ACACCGCCGC


(3a) FW ELP III TATATAGGTCTCGAGGGTGTACCAGGCGAAGGGGTGCCGG GTGTC

(3b) REV ELP III ATATATGGTCTCCGGCAGACCTTCACCCGGAACGCCACCCC LPETGG CCGGAACACCGCCGC

(4) REV ELP III ATATATGGTCTCCACCTTCACCCGGAACGCCACCCCCCGG AACACCGCCGC

(5) FW backbone ATATATGGTCTCCTGCCGGAAACCGGCGGCTAACTCGAGTA LPETGG AGATCCGGCTGC

(6) REV backbone ybbR

ATATATGGTCTCAGCCAGTTTAGAAGCGATGAATTCCAG

(7) FW backbone ybbR

GACTCTCTGGAATTCATCGCTTCTAAACTGGCTGGTCTCC AGGTGTGCCGGGA

(8) FW ELP II ybbR

TATATA GGTCTCCTGGCGGTACCAGGCGAAGGGGTGCCGG GTGTC

TATATAGGTCTCCTGGCGGTACCAGGCGAAGGCGTGCCGG (9) FW ELP III GTGTC ybbR

(10) FW ELP N Cys

GACTCTCTGGAATTCATCGCTTCTAAACTGGCTGGTCTCC (11) REV backbone TGCGTGCCGGGAGAAGGAG CCCGGCACAGCCAGTTTAGAAGCGATGAATTCCAGAGAG TCGGTCTCACATATGTATATC

Primers $1-7$ are employed for the cloning of the ELPs with 3 fragments growth every cycle. 1-4 are the primers necessary for insert amplification, 5-7 for the amplification of the backbone. Primers 8 and 9 are only important for ELP cloning procedures with the addition of one or two fragments. Primers 10 and 11 were used to change the 5' flanking site of the ELP gene from the gene for the ybbR-tag to a cysteine. DNA Sequence is styled in different ways: bold (annealing region), underlined ( $B s a \mathrm{I}$ recognition site), highlighted in grey (BsaI restriction site)

147 In the first round of PCR (see backbone PCR above, $55^{\circ} \mathrm{C} 7 \mathrm{~s}$ annealing), the backbone of a 148 modified pET28a vector (Merck KGaA, Darmstadt, Germany) was linearized. The PCR product 149 contained at the 5' end the sequence for a ybbR-tag (DSLEFIASKLA) and at the 3' end a C150 terminal Sortase recognition sequence (LPETGG) ${ }^{33,34}$. Sequences of all PCR fragments 151 (backbone, ELP I, II, III, IV) and a description for primer design (see Supporting Information, 
152 Primer 12) based on an original pET28a vector are attached in the supporting information (Fig.

153 S1 - S9, DNA Sequence 1-6 and Fig. S14-S18).

154

155 The superfolder GFP (sfGFP) plasmid was created with Gibson Assembly ${ }^{35}$. The gene (Addgene 156 ID: 58708$)^{36}$ was amplified with overlaps to match a linearized vector containing sequences 157 encoding N-terminal HIS $_{6}$-tag, a TEV protease cleavage site and two glycines (compare the PCR 158 program above; $55^{\circ} \mathrm{C}$ annealing and an extension time of 1 min. $30 \mathrm{~s}$; see Supporting 159 Information, DNA Sequence 8 and Protein Sequence 4).

160

161 All PCR products were digested $\left(37^{\circ} \mathrm{C}, 1-12 \mathrm{~h}\right)$ with FD-DpnI (Thermo Fisher Scientific Inc., 162 Waltham, MA, USA) and purified either with QIAquick PCR purification kit or gel extraction kit 163 (Qiagen, Hilden, Germany) (Supporting Information, Fig. S10, Fig. S13). DpnI was added to 164 digest the methylated plasmids serving as starting material (template) in the PCRs, to reduce 165 number of false positive clones in the following transformation.

167 Typically, a $25 \mu 1$ Golden Gate reaction (2.5 $\mu 1$ CutSmart buffer (10x), $1.25 \mu 1$ T7 ligase, $1.25 \mu 1$ 168 Bsal-HF and $2.5 \mu \mathrm{ATP}(10 \mathrm{mM})$, New England Biolabs, Ipswich, MA, USA) was set up. The 169 inserts were added in 10-fold molar excess to the backbone (ratio of $0.1 \mathrm{pmol}$ insert to $0.01 \mathrm{pmol}$ 170 backbone). The reaction was performed in a thermo cycler $\left(25 \times 37^{\circ} \mathrm{C} 2 \mathrm{~min}, 25^{\circ} \mathrm{C} 5 \mathrm{~min} ; 37^{\circ} \mathrm{C}\right.$ $\left.17110 \mathrm{~min} ; 80^{\circ} \mathrm{C} 10 \mathrm{~min}\right)$. For the Gibson Assembly reaction, $10 \mu 1$ of the master mix $(2 \mathrm{x}$, New 172 England Biolabs, Ipswich, MA, USA) were mixed with 0.01 pmol vector and 0.1 pmol insert. 173 The reaction was incubated for $1 \mathrm{~h}$ at $50^{\circ} \mathrm{C}$. For the replacement of the ybbR-tag with cysteine, 174 the PCR linearized product was first digested with $B s a I$-HF together with FD-DpnI $\left(1 \mathrm{~h}, 37^{\circ} \mathrm{C}, 5\right.$ 
$\left.175 \mathrm{~min}, 80^{\circ} \mathrm{C}\right)$. The reaction was supplied with $1 \mu \mathrm{l}$ of dNTPs $(10 \mathrm{mM}$, New England Biolabs, 176 Ipswich, MA, USA), $1 \mu$ l of Klenow Fragment (10 U/ $\mu \mathrm{L}$, Thermo Fisher Scientific Inc., 177 Waltham, MA, USA), and incubated $\left(37^{\circ} \mathrm{C}, 15 \mathrm{~min}\right.$, and $\left.75^{\circ} \mathrm{C}, 10 \mathrm{~min}\right)$. After a gel extraction, 178 the corresponding band was excised and a blunt end reaction (6.5 $\mu 1$ PCR product, $1 \mu 1$ ATP (10 $179 \mathrm{mM}), 1 \mu \mathrm{l}$ CutSmart buffer (10x), $0.5 \mu \mathrm{l}$ PEG-6000, $1.0 \mu 1 \mathrm{~T} 4$ Polynucleotide Kinase, $1.0 \mu 1 \mathrm{~T} 4$ 180 Ligase) was set up $\left(37^{\circ} \mathrm{C} 15 \mathrm{~min}, 22^{\circ} \mathrm{C} 45 \mathrm{~min}, 80^{\circ} \mathrm{C} 7 \mathrm{~min}\right)$.

181 In case of the Golden Gate reaction, $10 \mu 1$ and in case of the Gibson Assembly or the blunt end 182 ligation $2 \mu \mathrm{l}$ were used to transform DH5 $\alpha$ cells (Life Technologies GmbH, Frankfurt, Germany; $18330 \mathrm{~min}$ on ice, $42^{\circ} \mathrm{C} 1 \mathrm{~min}, 1 \mathrm{~h} 37^{\circ} \mathrm{C}$ ). The transformed culture was plated on appropriate 184 antibiotic LB-Agar plates. A small number $(<10)$ of clones were analyzed by colony PCR, or 185 analytical restriction digestion (FD-EcoRI, Thermo Fisher Scientific Inc., Waltham, MA, USA) 186 followed by sequencing (Supporting Information, Tab S1).

188 Protein Expression. For ELP expression, chemically competent E. coli NiCo21(DE3) (New 189 England Biolabs, Ipswich, MA, USA) were transformed with 50 ng plasmid DNA ${ }^{37}$. The cells 190 were incubated in kanamycin containing, autoinducing ZYM-5052 media (supplemented with an 191 amino acid mix $0.1 \mathrm{mg} / \mathrm{ml}) 24 \mathrm{~h}$ at $25^{\circ} \mathrm{C}^{38-40}$. After harvesting, ice cooled cells were lysed using 192 sonication (Bandelin Sonoplus GM 70, Tip: Bandelin Sonoplus MS 73, Berlin, Germany; 40 \% 193 Power, $30 \%$ Cycle $2 \times 10 \mathrm{~min})$. The supernatant of the lysate $\left(15000 \mathrm{~g}, 4^{\circ} \mathrm{C}, 1 \mathrm{~h}\right)$ was heated to $19460^{\circ} \mathrm{C}$ for $30 \mathrm{~min}$ to denature most of the $E$. coli host proteins. In a second step, the collapsed 195 ELPs within this clouded solution were rehydrated by incubating under continuous mixing for 2 $196 \mathrm{~h}$ at $4^{\circ} \mathrm{C}$. This allowed the resolubilization of the ELPs while the precipitated host proteins 197 remained insoluble. A centrifugation step $\left(15000 \mathrm{~g}, 4^{\circ} \mathrm{C}, 30 \mathrm{~min}\right)$ was used to separate the 
198 soluble ELPs and remaining proteins from precipitated cell debris. The clear supernatant turned 199 immediately cloudy after adding $1 \mathrm{M}$ acetate buffer (final concentration $50 \mathrm{mM}, \mathrm{pH} 3.5$ ), and 2 $200 \mathrm{M} \mathrm{NaCl}$ in crystalline form. The mixture was incubated for $30 \mathrm{~min}$ at $60^{\circ} \mathrm{C}$. The collapsed ELPs 201 were collected by centrifugation $\left(3220 \mathrm{~g}, 40^{\circ} \mathrm{C}, 75 \mathrm{~min}\right)$. The obtained pellet was re-solubilized 202 in $50 \mathrm{mM}$ TRIS- $\mathrm{HCl}(\mathrm{pH} 7.0)$ and incubated over night at $4^{\circ} \mathrm{C}$. The remaining precipitated debris 203 were removed by a final centrifugation step $\left(3220 \mathrm{~g}, 4^{\circ} \mathrm{C}, 60 \mathrm{~min}\right)$. The supernatant was mixed 204 again with acetate buffer and sodium chloride to collapse the ELPs. After the heated incubation 205 and centrifugation step, the pellet was resolubilized in buffer (50 mM TRIS-HCl, $\mathrm{pH} 7.0)^{14,41}$.

206 The purity of the ELP was confirmed by SDS-PAGE (Any $\mathrm{kD}^{\mathrm{TM}}$ Mini-PROTEAN ${ }^{\circledR}$ Stain207 Free $^{\mathrm{TM}}$ Gels, Bio-Rad Laboratories GmbH, Hercules, CA, USA), in order to detect any 208 remaining contaminant host proteins. The ELPs were labeled with CoA-647 (New England 209 Biolabs (Ipswich, MA, USA) and $\operatorname{Sfp}\left(37^{\circ} \mathrm{C}, 1 \mathrm{~h}, 5 \mathrm{mM} \mathrm{MgSO}_{4}\right)$ to visualize them. After 210 labeling, the ELPs were mixed with 6x Loading buffer and heated to $95^{\circ} \mathrm{C}$ for $10 \min ^{42}$. Usually 211 a purity grade of $>95 \%$ was obtained. Purity analysis was performed by overlaying the UV active 212 Stain-Free $^{\mathrm{TM}}$ technology from Bio-Rad (labeling all tryptophan side groups of E. coli host 213 proteins) and a fluorophore specific red channel for the CoA-647-ELP constructs (Supporting 214 Information Fig. S11). MALDI-TOF analysis of ELP samples $\mathrm{ELP}_{30^{-50}}$ was performed to 215 increase confidence in the high purity of the samples (Supporting Information, Fig. S19). ELPs 216 were stored at $4^{\circ} \mathrm{C}$ in $50 \mathrm{mM}$ TRIS-HCl, $\mathrm{pH}$ 7.0.

218 The final ELP concentration was photometrically determined at $205 \mathrm{~nm}$ (Ultrospec 3100 pro, 219 Amersham Biosciences (Amersham, England) and TrayCell (Hellma GmbH \& Co. KG, 220 Müllheim, Germany) $)^{43}$. 
222 For the expression of $\mathrm{HIS}_{6}$-TEV-GG-sfGFP, $50 \mathrm{ng}$ plasmid DNA was used to transform E. coli 223 NiCo21(DE3) cells. Kanamycin containing, autoinducing ZYM-5052 growth media was 224 inoculated with an overnight culture ${ }^{38}$. After $24 \mathrm{~h}$ incubation at $25^{\circ} \mathrm{C}$ the cells were harvested, 225 lysed and centrifuged as described above. The supernatant was applied on a HisTrap FF (GE 226 Healthcare Europe GmbH, Freiburg, Germany). After washing five times with wash buffer (25 $227 \mathrm{mM}$ TRIS-HCl pH 7.8, 300 mM NaCl, 20 mM Imidazole, Tween $200.25 \%$ (v/v), $10 \%$ (v/v) 228 glycerol) the bound protein was eluted (25 mM TRIS-HCl pH 7.8, $300 \mathrm{mM} \mathrm{NaCl}, 300 \mathrm{mM}$ 229 Imidazole, Tween $200.25 \%(\mathrm{v} / \mathrm{v}), 10 \%(\mathrm{v} / \mathrm{v})$ glycerol).

231 HIS $_{6}$-TEV-GG-sfGFP fusion protein (TEV cleavage site: ENLYFQG) was dialyzed immediately 232 after elution with the TEV protease $\left(4^{\circ} \mathrm{C}, 50 \mathrm{mM}\right.$ TRIS-HCl, $\left.\mathrm{pH} 7.0\right)$ overnight. The cleaved 233 product was separated from the uncleaved construct by applying the reaction mix on a HisTrap 234 FF $5 \mathrm{ml}$ column. The successfully cut fragment in the flow through was collected. The fraction 235 was dialyzed against $50 \mathrm{mM}$ TRIS-HCl, $\mathrm{pH} 7.0$ and stored in $50 \%(\mathrm{v} / \mathrm{v})$ glycerol at $-80^{\circ} \mathrm{C}$. The 236 purity of the elution and the cleaved fraction was analyzed via a SDS-PAGE analysis. The 237 specific extinction coefficient of GFP at $485 \mathrm{~nm}$ was used to determine the concentration of GG238 sfGFP.

240 Turbidity measurements. For the turbidity measurements, a photometer with a Peltier heating 241 element was used (JASCO V-650, JASCO Germany GmbH, Gross-Umstadt, Germany). The 242 turbidity was determined at $350 \mathrm{~nm}$ while the temperature was ramped at a rate of $2^{\circ} \mathrm{C} / \mathrm{min}$. 243 Measurements were taken every $0.5^{\circ} \mathrm{C}$ between 20 and $80^{\circ} \mathrm{C}$. ELPs were dialyzed against double 
244 distilled water, mixed with a buffer stock solution (1 M TRIS-HCl, pH 7.0), sodium chloride 245 stock solution ( $3 \mathrm{M}$ or $5 \mathrm{M}$ ) and adjusted with water to the desired final concentration.

247 For $\mathrm{NaCl}$ titration, $100 \mu \mathrm{M}$ of the ELP constructs were tested in a range of $0-3 \mathrm{M}$ sodium 248 chloride. The $6 \mathrm{x}$ ELP construct was also probed in a concentration range of $25 \mu \mathrm{M}-200 \mu \mathrm{M}$ 249 with different $\mathrm{NaCl}$ concentrations.

250

251 For $\mathrm{pH}$ titrations, stock solutions of $0.1 \mathrm{M}$ phosphate-citrate buffer at different $\mathrm{pH}$ values were 252 mixed with solutions of water solubilized ELPs. Hereby a final concentration of $0.05 \mathrm{M}$ of the 253 phosphate-citrate buffer was obtained.

255 Data analysis of the transition temperature curves (for $\mathrm{NaCl}, \mathrm{pH}$, concentration dependency and 256 PEG-ELP fusions) was performed by fitting the measured data points with a four-parameter 257 logistic function to obtain the corresponding transition temperature.

259 Sortase and Sfp-mediated protein ligation. For highest ligation efficiencies, enhanced Sortase 260 (eSortase) was used in the reaction ${ }^{44}$. The reaction conditions for both Sfp and eSortase enzymes 261 were chosen according their reported reaction maxima to achieve highest activities ${ }^{28}$. ELPs in 262 excess were added to a solution containing $50 \mathrm{mM}$ TRIS-HCl, pH 7.5, $15 \mu \mathrm{M}$ ELP, $0.5 \mu \mathrm{M}$ GG263 sfGFP, $0.2 \mu \mathrm{M}$ eSortase, $1 \mu \mathrm{M}$ Sfp, $5 \mathrm{mM} \mathrm{CaCl}_{2}, 5 \mathrm{mM} \mathrm{MgCl} 2,5 \mu \mathrm{M}$ CoA-647. The ligation 264 reaction was incubated for $2 \mathrm{~h}$ at $37^{\circ} \mathrm{C}$.

265 
266 Cysteine-Maleimide bioconjugation reaction. Cysteine-containing ELPs were reduced with 5 $267 \mathrm{mM}$ tris(2-carboxyethyl)phosphine (TCEP, (Thermo Fisher Scientific Inc., Waltham, MA, 268 USA)). After the removal of TCEP with Zeba ${ }^{\mathrm{TM}}$ Spin Desalting Columns 7K (Thermo Fisher 269 Scientific Inc., Waltham, MA, USA) cysteine-ELPs were mixed with Alexa $647-C 2-M a l e i m i d e$ 270 (Thermo Fisher Scientific Inc., Waltham, MA, USA) and incubated for $1 \mathrm{~h}$ at $37^{\circ} \mathrm{C}(100 \mathrm{mM}$ 271 TRIS-HCl, pH 7.0) (Supporting Information, Fig. S20).

272 PEG (MW: 20,000 Da, $\alpha$-Methoxy- $\omega$-maleimide, Rapp Polymere GmbH, Tübingen, Germany) 273 was used in different molar ratios in the bioconjugation reaction with cysteine-ELP 60 or ELP $_{60}$. $27475 \mu \mathrm{M}$ of the reduced ELPs were mixed with TRIS-HCl (pH 7.0, $100 \mathrm{mM})$, PEG, and incubated 275 for $1 \mathrm{~h}$ at room temperature. After that they were mixed with $5 \mathrm{M} \mathrm{NaCl}$ and to a final 276 concentration of $3 \mathrm{M} \mathrm{NaCl}$ and their cloud point was determined as described above.

278 RESULTS AND DISCUSSION

279 Our sequence independent Golden Gate-based method provides an easy way to create defined 280 repetitive DNA sequences ${ }^{26}$. We designed and produced gene cassettes encoding repetitive 281 proteins several hundreds of amino acids in length. Fig. 1 outlines the principle of primer design 282 and the following logical and stepwise workflow. The sequence of the starting synthetic gene 283 was designed in such a way that the codon usage within the first and last 15 nucleotides was 284 unique within the otherwise repetitive $150 \mathrm{bp}$ sequence. This was necessary to ensure specific 285 annealing of primers at the 5' and 3' end. Desired modifications were introduced by overhangs 286 of the primers at their 5' end (i.e. BsaI recognition site) or at their 3' region (codon shuffling of 287 nucleotides). It was then possible to create $150 \mathrm{bp}$ ELP genes with different flanking regions 
288 from the same template (Primers 1-3; Fig. 1 A) using PCR primers that annealed at the 5' and 3' 289 ends of the synthetic gene.

290

291 In the first amplification and linearization reaction of the plasmid, primers annealed at the 292 desired ELP gene insertion site, i.e. at the opening location on the plasmid during the first PCR. 293 In our case this was downstream of the T7 promoter and upstream of the T7 terminator (see 294 Supporting Information Fig. S8 and S9). However, due to the freedom of primer design and 295 plasmid choice, the insertion site can in principle be anywhere in the plasmid. The primers 296 linearized the plasmid and introduced tags at the 5' (ybbR-tag) and 3' (Sortase c-tag) prime ends, 297 as well as BsaI recognition sites (Primers 5, 6; Vector A; Fig. 1 A). In our case, a modified 298 pET28a vector, already containing a ybbR-site downstream of the T7 promotor immediately 299 following the start codon AUG, served as template. Hence, only the Sortase c-tag was newly 300 introduced (see Supporting Information for primers for the standard pET28a vector). The 301 continuing general ELP expansion principle relies on having three different PCR amplified ELP 302 fragments (I, II, III) with different codon usages at their 5' and 3' end, within the BsaI-restriction 303 site (Supporting Information Fig. S1-S6). This design made logical and block-wise gene 304 assembly possible. The selected primers introduced a shuffled 3' end which matched the 5' end 305 of the subsequent fragment. In the first ELP assembly round, the 5' end of fragment I matched 306 the ybbR-tag of the linearized backbone. The 3' end of fragment III had compatible sticky ends 307 with the Sortase c-tag of the linearized plasmid (Fig. 1 B, 1st round). After successful annealing 308 of sticky ends, the T7 ligase covalently linked the three ELP fragments seamlessly into the 309 plasmid without any undesirable cloning scars in between. 
311 The forward primer (Fig. 1 A, $2^{\text {nd }}$ : Primer 7) for the following plasmid linearization rounds 312 annealed at a different site within the ELP-containing plasmid, compared to the initial 313 linearization round (Fig. $1 \mathrm{~A}, 1^{\text {st }}$ : Primer 5). It annealed at the ybbR-tag and the 5' end of the

314 ELP gene. Right in between the two coding regions, a non-annealing loop encoding a BsaI 315 recognition site was introduced (Fig. $1 \mathrm{~A} 2^{\text {nd }}$, and Fig. $1 \mathrm{~B} 2^{\text {nd }}$ round) with the primer. The 316 annealing at the ybbR-tag was necessary to ensure high temperature-dependent primer annealing 317 specificity at the very 5' end of the ELP gene, otherwise the primer would anneal at every 318 fragment I throughout the whole assembled ELP gene cassette. High annealing temperatures 319 minimize undesired PCR side products, i.e. only partly ELP-containing, linearized vectors. The 320 reverse primer was the same for all plasmid linearization reactions (Fig. 1 A; Vector B). After 321 the restriction digestion reaction, the linear plasmid now had a Sortase c-tag sticky end at the 3' 322 end and an ELP fragment I sticky end at the 5' end.

324 Now only the last ELP fragment (Fig. 1 A, Insert IV) had to be amplified with a different reverse 325 primer (Fig. 1 A, Primer 4) to yield a PCR product with a compatible 3' end to the already 326 existing ELP cassette. The growing ELP insert in the plasmid always started with fragment I. 327 This made the reuse of the amplified insert sequences (I, II, IV) for every following expansion 328 cloning round possible (Fig .1 B,$>3^{\text {rd }}$ rounds).

330 This method not only allows a logical assembly of repetitive gene patterns, but also makes the 331 modification of flanking regions or mutation of the first base pairs at 5' end 3' end possible. For 332 example, we introduced two glutamates in each of the fragments at their 5' and 3' ends by 333 changing the codon from the ' $\mathrm{X}$ ' guest residue at the 5' and 3' end of the VPGXG motif to a 
334 glutamate (VPGEG). The primers did not align completely with the template and introduced the

335 glutamate mutation during PCR amplification. The chemically synthesized sequence also had

336 some minor mistakes at the 3' end, which were corrected with primers within the initial PCR.

337 The final ELP substructure of all ELPs used in this study consisted of 10 pentapeptide repeats

$338\left(\mathrm{VPGXG}_{10}, \mathrm{X}\right.$ being $\left[\mathrm{EV}_{4} \mathrm{~A}_{2} \mathrm{G}_{2} \mathrm{E}\right]$ ). For the rest of the manuscript this motif is referred as $\mathrm{ELP}_{\mathrm{n}}$

339 with $\mathrm{n}$ being the number of pentapeptide repeats of this motif (see Supporting Information, DNA

340 Sequence 2, Protein Sequence 2 and DNA Sequence 7, Protein Sequence 3).

342 We ligated three $150 \mathrm{bp}$ fragments with a linearized vector of choice in one step. It was possible 343 to modify the $5^{\prime}$ and $3^{\prime}$ ends of the fragments with overhang primers prior to ligation, in our case 344 with an N-terminal ybbR and a C-terminal Sortase tag (Fig. 1 B). Overall seven different ELP 345 constructs were used in this study for biophysical characterization of the peptide sequence, while 346 ten were successfully cloned. The largest ELP gene contained 120 pentapeptide repeats. All ELP 347 constructs were built with the four different ELP PCR products from the same batch. PCR gels 348 from the fragments and an overview of cloning efficiencies can be found in the supporting 349 information (Fig. S9 and Tab. S1). Typical yields after the purification were $56-138 \mathrm{mg}$ 350 Protein/l culture, while the $\mathrm{ELP}_{10}$ repeat had the lowest yield ( $2 \mathrm{mg}$ Protein/l culture).

352 Tab. 2 shows biophysical characteristics of the ELPs characterized in this study. Each ELP was 353 produced with a ybbR-tag at the N-terminus and a Sortase c-tag at the C-terminus. In the bottom 354 right corner of the schematic (Fig. 1), FD-EcoRI digested plasmids are shown on an agarose gel. 355 The gel analysis shows the successful construction of plasmids containing 10 to 120 356 pentapeptide repeats. 
357 Table 2. Biophysical properties of the characterized ELP constructs.

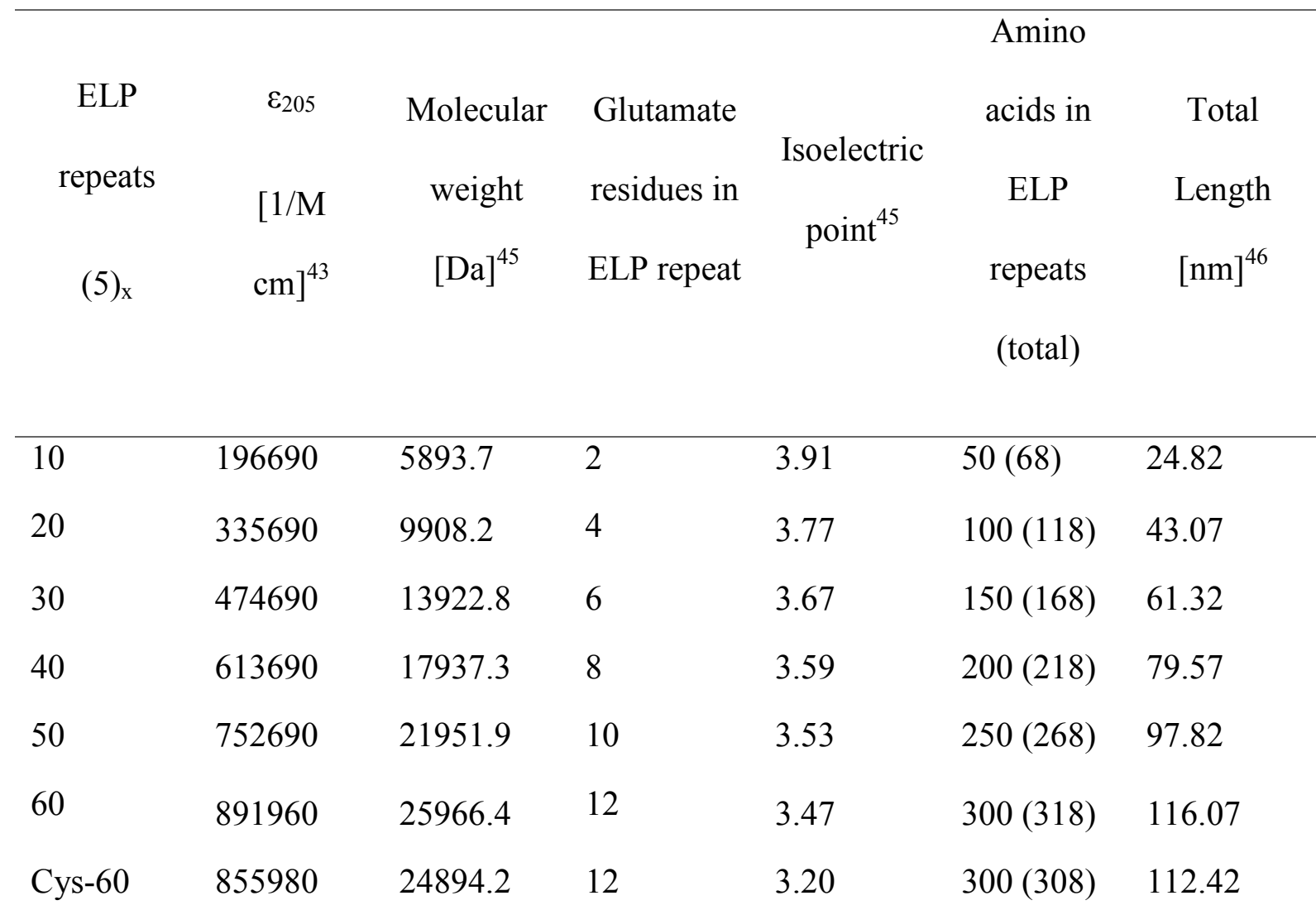

358

359 Following successful cloning, expression and purification, we tested the functionality of the 360 attached terminal tags. Fig. 2 A shows the scheme for post-translational protein ligation 361 reactions. The ELPs of varying lengths contain an N-terminal ybbR-tag and a C-terminal Sortase 362 recognition sequence (i.e., LPETGG). Subpanel 2 B to $2 \mathrm{C}$ show an SDS-PAGE image of the 363 same gel with different excitation and emission filters. Using a reaction catalyzed by Sfp, it was 364 possible to fuse a fluorescently labeled CoA-647 to the ELP (N-terminal ybbR-tag). Results of 365 the specific excitation for the CoA-647 dye are shown in 2 B. Brightest are the CoA-647-ELP 366 fusions proteins, but also the CoA-647-ELP-sfGFP fusion proteins are visible above the bright 367 monomer band. Fully denatured proteins appear slightly higher in the gel due to their different 
368 running behavior. The Sortase-tag was simultaneously utilized for fusion of different proteins to 369 the ELP sequences (C-terminal LPETGG). A GG-sfGFP was fused to the ELPs, which was 370 excited with blue LED light and detected within the green emission of sfGFP (Fig. 2 C). Non371 ligated and non-denaturated GFP appears at the top of the gel, since it does not run according its 372 molecular weight in its native (i.e., correctly folded) state (see Supporting Information, Fig. 373 S12). No GFP fluorescence is visible in the heated samples due to complete denaturation of the 374 GFP chromophore. Panel 2 D shows an overlay of B and C, visualizing the successful post375 translational ligation of GG-sfGFP and CoA-647 to the different ELP peptides within a one-pot 376 reaction. The ligation efficiency of the Sortase never goes to $100 \%$ completion. Due to the 377 Sortase reaction mechanism, a dynamic equilibrium is eventually reached and complete fusion of 378 GG-sfGFP to ELP is therefore not to be expected ${ }^{47}$.

380 After confirming the biochemical accessibility and functionality of the terminal ybbR- and 381 Sortase-tags, we characterized the phase behavior of the modified ELPs. Fig. 3 presents an 382 overview of the lower critical solution temperatures (LCSTs) of the characterized ELPs under 383 various conditions. First the temperature dependence of the $\mathrm{ELP}_{10^{-60}}$ constructs were probed 384 against different sodium chloride concentrations, at neutral pH (50 mM TRIS-HCl, pH 7.0) (Fig. $3853 \mathrm{~A}$ ). The 10 pentapeptide repeat ELP did not collapse below $80^{\circ} \mathrm{C}$, which is in agreement with 386 the remainder of the data set if one looks at the increasing transition temperature with decreasing 387 size of the construct. The 20 pentapeptide ELP repeat, for example, only collapsed with $3 \mathrm{M}$ of 388 sodium chloride at $60^{\circ} \mathrm{C}$. Fig. 3 B clarifies the correlation between salt concentration, molecular 389 mass and transition temperatures. Only the longest ELP construct collapsed across all given 390 sodium chloride concentrations in the temperature range from 20 to $80^{\circ} \mathrm{C}$. Salt-induced cloud 391 point shifts are a well known characteristic of ELPs ${ }^{15,24,48}$. 
393 The incorporation of two glutamates per ten pentapeptides resulted in $\mathrm{pH}$-dependent transitions.

394 ELPs with glutamates were expected to show $\mathrm{pH}$-responsiveness. Above their $\mathrm{pK}_{\mathrm{a}}$ the ELPs have 395 a relatively high transition temperature, since the glutamates are deprotonated and ionized and 396 therefore electrostatically repel each other. Below or close to their corresponding $\mathrm{pK}_{\mathrm{a}}$, the 397 transition temperature significantly decreases due to protonation and neutralization of the 398 negative charge (Fig. 3 C). The decreasing influence of salt at lower $\mathrm{pH}$ is similar to that 399 demonstrated by MacKay et al. ${ }^{49}$. Fig. 3 D illustrates the dependence of transition temperature 400 on the ELP concentration. At concentrations above $100 \mu \mathrm{M}$, the 60 pentapeptide ELP $(150,200$ $401 \mu \mathrm{M})$ already collapsed at room temperature, hence it was not possible to determine an exact 402 transition point. The ligated product between the 60 pentapeptide ELP repeat and the sfGFP did 403 not show any transition compared to the pure 60 pentapeptide ELP (data not shown). This 404 concentration dependence is also a well-known characteristic of ELPs ${ }^{10}$.

405

406 This PCR based method can also be employed to change the flanking sequences of the ELP very 407 quickly. Fig. 4 A shows the underlining principle of the cloning procedure used to install 408 cysteine as an end residue with no cloning scar. Due to the repetitive structure of the ELP gene it 409 was necessary to design primers which anneal at the site of replacement. A BsaI recognition loop 410 between ELP annealing and deletion annealing site was necessary to remove the deletion site 411 again afterwards. BsaI digestion left incompatible 5' and 3' sticky ends, therefore a Klenow 412 Fragment was employed to fill the ends. A standard blunt end ligation circularized the linear 413 plasmid (Fig. 4A and Supporting Information: Fig. S13-S18). This procedure provided an N414 terminal cysteine that could be used for bioconjugations to various (macro)molecules (see 415 Supporting Information, DNA Sequence 9, Protein Sequence 5). The cysteine in the ELP is able 
416 to form disulfide bonds with different cysteine containing proteins, but also is able to be clicked 417 to other reactive groups like maleimide (i.e. a maleimide-PEG (Fig. 4 B)). The cloud point 418 determination of Fig. 4 C shows the influence of PEG conjugation on the ELP cloud point, 419 confirming a shift towards higher temperatures (Fig. 4 C, CYS-ELP ${ }_{60}$ ) due to conjugation of the 420 hydrophilic synthetic polymer. However, the same PEG added to a solution of the same ELP that 421 lacked the cysteine functionality did not significantly influence the cloud point (Fig. 4 C, ELP 60 ). 422

\section{CONCLUSION}

424 The presented approach shows an alternative way to create fast and convenient functional ELPs 425 with sequence lengths up to 600 amino acids, or hundreds of $\mathrm{nm}$ in stretched contour length. It 426 allows a straightforward fusion of gene sequences encoding the ELP repeats without any prior 427 vector modifications. We used this approach to demonstrate facile incorporation of functional 428 peptide tags as end groups into ELPs. We demonstrate how this approach was useful for 429 developing end-labeled ELPs through enzyme-mediated site-specific ligation to organic dyes and 430 fluorescent proteins, and show how terminal cysteine incorporation expands the versatile toolbox 431 of bioconjugation opportunities. Since we used a PCR and primer-based approach, our method is 432 essentially sequence independent and does not leave cloning scars. In the future we anticipate 433 that such a tool for straightforward end-group modification of ELPs will prove useful for 434 developing custom engineered macromolecular systems.

436 ASSOCIATED CONTENT

\section{Supporting Information}


438 Additional information including sequence data (DNA and Protein sequences), extended cloning

439 procedures and gel pictures of PCR products and protein purification steps.

440 This material is available free of charge via the Internet at http://pubs.acs.org.

441

442 AUTHOR INFORMATION

443 Corresponding Author

444 e-Mail: *michael.nash@1mu.de

445 Author Contributions

446 W.O., M.A.N. and H.E.G. designed the research; W.O. and T. N. performed experiments; W.O.

447 performed data analysis; W.O., and M.A.N. co-wrote the manuscript.

$448 \quad$ Notes

449 The authors declare no competing financial interests.

450

451 ACKNOWLEDGMENT

452 We gratefully acknowledge funding from an advanced grant of the European Research Council

453 (Cellufuel Grant 294438), SFB 863 and the Excellence Cluster Center for Integrated Protein

454 Science Munich. M.A.N. acknowledges funding from Society in Science - The Branco Weiss

455 Fellowship program administered by ETH Zürich, Switzerland. We thank the systems biophysics

456 group of Professor Dieter Braun (Ludwig-Maximilians-Universität München) for the access to

457 the JASCO V-650. The authors thank Anna Krautloher for initial concentration determinations

458 of the ELPs at $205 \mathrm{~nm}$. We acknowledge Markus Jobst for his advice on the ongoing manuscript.

459 We thank the following people for providing material to this study: Ellis Durner (eSortase), 
460 Angelika Kardinal (TEV protease) and Diana Pippig (Sfp), and Arne Goldenbaum for assistance 461 in lab work. We are grateful for the MALDI-TOF analysis of ELP samples by the protein 462 analysis group of the Ludwig-Maximilians-Universität München (Professor Axel Imhof, Dr. 463 Andreas Schmidt, Dr. Ignasi Forné and Pierre Schilcher).

\section{REFERENCES}

465 (1) Pack, D. W.; Hoffman, A. S.; Pun, S.; Stayton, P. S. Nat. Rev. Drug Discov. 2005, 4 (7), 466 581-593.

467 (2) Onaca, O.; Enea, R.; Hughes, D. W.; Meier, W. Macromol. Biosci. 2009, 9 (2), 129-139.

468 (3) Nash, M. A.; Waitumbi, J. N.; Hoffman, A. S.; Yager, P.; Stayton, P. S. ACS Nano 2012, $469 \quad 6(8), 6776-6785$.

470 (4) Nash, M. A.; Gaub, H. E. ACS Nano 2012, 6 (12), 10735-10742.

471 (5) Urry, D. W.; Hugel, T.; Seitz, M.; Gaub, H. E.; Sheiba, L.; Dea, J.; Xu, J.; Parker, T. 472 Philos. Trans. R. Soc. B Biol. Sci. 2002, 357 (1418), 169-184.

473 (6) Wolff, M.; Braun, D.; Nash, M. A. Anal. Chem. 2014, 86 (14), 6797-6803.

474 (7) Urry, D. W.; Haynes, B.; Harris, R. D. Biochem. Biophys. Res. Commun. 1986, 141 (2), 475 749-755.

476 (8) Tatham, A. S.; Shewry, P. R. Trends Biochem. Sci. 2000, 25 (11), 567-571.

477 (9) Urry, D. W.; Haynes, B.; Zhang, H.; Harris, R. D.; Prasad, K. U. Proc. Natl. Acad. Sci. U. 478 S. A. 1988, $85(10), 3407-3411$.

479 (10) Meyer, D. E.; Chilkoti, A. Biomacromolecules 2004, 5 (3), 846-851.

480 (11) Urry, D. W. J. Phys. Chem. B 1997, 101 (51), 11007-11028.

481 (12) Bataille, L.; Dieryck, W.; Hocquellet, A.; Cabanne, C.; Bathany, K. PROTEIN Expr. $482 \quad$ Purif. 2015, 110, 165-171.

483 (13) Bellucci, J. J.; Amiram, M.; Bhattacharyya, J.; McCafferty, D.; Chilkoti, A. Angew. 484 Chemie - Int. Ed. 2013, 52 (13), 3703-3708.

485 (14) Meyer, D. E.; Chilkoti, A. Nat. Biotechnol. 1999, 17 (11), 1112-1115.

486 (15) Gagner, J. E.; Kim, W.; Chaikof, E. L. Acta Biomater. 2014, 10 (4), 1542-1557.

487 (16) Kojima, C.; Irie, K. Biopolymers 2013, 100 (6), 714-721.

488 (17) Christensen, T.; Hassouneh, W.; Trabbic-Carlson, K.; Chilkoti, A. Biomacromolecules 
489

490

491

492

493

494

495

496

497

498

499

500

501

502

503

504

505

506

507

508

509

510

511

512

513

514

515

516

517

518

519

520

521

2013, 14 (5), 1514-1519.

(18) McDaniel, J. R.; Radford, D. C.; Chilkoti, A. Biomacromolecules 2013, 14 (8), 28662872.

(19) Rousseau, R.; Schreiner, E.; Kohlmeyer, A.; Marx, D. Biophys. J. 2004, 86 (3), 13931407.

(20) Qin, G.; Glassman, M. J.; Lam, C. N.; Chang, D.; Schaible, E.; Hexemer, A.; Olsen, B. D. Adv. Funct. Mater. 2014, 25 (5), 729-738.

(21) Glaves, R.; Baer, M.; Schreiner, E.; Stoll, R.; Marx, D. ChemPhysChem 2008, 9 (18), 2759-2765.

(22) Wang, H.; Cai, L.; Paul, A.; Enejder, A.; Heilshorn, S. C. Biomacromolecules 2014, 15 (9), 3421-3428.

(23) Van Eldijk, M. B.; Smits, F. C. M.; Vermue, N.; Debets, M. F.; Schoffelen, S.; Van Hest, J. C. M. Biomacromolecules 2014, 15 (7), 2751-2759.

(24) Meyer, D. E.; Chilkoti, A. Biomacromolecules 2002, 3 (2), 357-367.

(25) Amiram, M.; Quiroz, F. G.; Callahan, D. J.; Chilkoti, A. Nat. Mater. 2011, 10 (2), 141148.

(26) Engler, C.; Kandzia, R.; Marillonnet, S. PLoS One 2008, 3 (11), e3647.

(27) McDaniel, J. R.; MacKay, J. A.; Quiroz, F. G.; Chilkoti, A. Biomacromolecules 2010, 11 (4), 944-952.

(28) Yin, J.; Lin, A. J.; Golan, D. E.; Walsh, C. T. Nat. Protoc. 2006, 1 (1), 280-285.

(29) Huber, M. C.; Schreiber, A.; Wild, W.; Benz, K.; Schiller, S. M. Biomaterials 2014, 35 (31), 8767-8779.

(30) Christensen, T.; Amiram, M.; Dagher, S.; Trabbic-Carlson, K.; Shamji, M. F.; Setton, L. A.; Chilkoti, A. Protein Sci. 2009, 18 (7), 1377-1387.

(31) Beerli, R. R.; Hell, T.; Merkel, A. S.; Grawunder, U. PLoS One 2015, 10 (7), e0131177.

(32) Qi, Y.; Amiram, M.; Gao, W.; McCafferty, D. G.; Chilkoti, A. Macromol. Rapid Commun. 2013, 34, 1256-1260.

(33) Mazmanian, S. K.; Liu, G.; Ton-That, H.; Schneewind, O. Science 1999, 285 (5428), 760763.

(34) Yin, J.; Straight, P. D.; McLoughlin, S. M.; Zhou, Z.; Lin, A. J.; Golan, D. E.; Kelleher, N. L.; Kolter, R.; Walsh, C. T. Proc. Natl. Acad. Sci. U. S. A. 2005, 102 (44), 1581515820 .

(35) Gibson, D. G.; Young, L.; Chuang, R.-Y.; Venter, C. J.; Hutchison III, C. A.; Smith, H. O. 
522

523

524

525

526

527

528

529

530

531

532

533

534

535

536

537

538

539

540

541

542

543

544

545

Nat. Methods 2009, 6 (5), 343-347.

(36) Otten, M.; Ott, W.; Jobst, M. A.; Milles, L. F.; Verdorfer, T.; Pippig, D. A.; Nash, M. A.; Gaub, H. E. Nat. Methods 2014, 11 (11), 1127-1130.

(37) Robichon, C.; Luo, J.; Causey, T. B.; Benner, J. S.; Samuelson, J. C. Appl. Environ. Microbiol. 2011, 77 (13), 4634-4646.

(38) Studier, F. W. Protein Expr. Purif. 2005, 41, 207-234.

(39) Collins, T.; Azevedo-Silva, J.; da Costa, A.; Branca, F.; Machado, R.; Casal, M. Microb. Cell Fact. 2013, 12 (21), 1-16.

(40) Chow, D. C.; Dreher, M. R.; Trabbic-Carlson, K.; Chilkoti, A. Biotechnol. Prog. 2006, 22 (3), 638-646.

(41) MacEwan, S. R.; Hassouneh, W.; Chilkoti, A. J. Vis. Exp. 2014, No. 88, e51583.

(42) Laemmli, U. K. Nature 1970, 227 (5259), 680-685.

(43) Anthis, N. J.; Clore, G. M. Protein Sci. 2013, 22 (6), 851-858.

(44) Dorr, B. M.; Ham, H. O.; An, C.; Chaikof, E. L.; Liu, D. R. Proc. Natl. Acad. Sci. 2014, 111 (37), 13343-13348.

(45) Gasteiger, E.; Hoogland, C.; Gattiker, A.; Duvaud, S.; Wilkins, M. R.; Appel, R. D.; Bairoch, A. In The Proteomics Protocols Handbook; 2005; pp 571-607.

(46) Dietz, H.; Rief, M. Proc. Natl. Acad. Sci. U. S. A. 2006, 103 (5), 1244-1247.

(47) Theile, C.; Witte, M.; Blom, A. Nat. Protoc. 2013, 8 (9), 1800-1807.

(48) Catherine, C.; Oh, S. J.; Lee, K.-H.; Min, S.-E.; Won, J.-I.; Yun, H.; Kim, D.-M. Biotechnol. Bioprocess Eng. 2015, 20 (3), 417-422.

(49) MacKay, J. A.; Callahan, D. J.; FitzGerald, K. N.; Chilkoti, A. Biomacromolecules 2010, 11 (11), 2873-2879. 


\section{FIGURE CAPTIONS}

547 Figure 1. Cloning schematic

548

549

550

551

552

553

554

555

556

557

558

559

560

561

562

563

564

565

566

567

568

569

570

571

572

573

574

575

576

577

578

579

580

581

582

583

584

585
(A) The schematic describes the process of sequence independent PCR amplification of unique inserts (I, II, III) from the same template. The amplification of the first backbone (plasmid A) enables subcloning of the first three inserts, which leads to plasmid B. Plasmid B is linearized at the N-terminal ybbR-tag, as are all the following backbones. The new ELP amplicons can always be inserted upstream of the old ELP repeats. (B) Repetitive rounds of cloning add subsequently more ELP inserts until the desired length is achieved.

Figure 2. Post-translational ligation of the ELP peptide

(A) Schematic of the ELP constructs containing a N-terminal ybbR-tag and a C-terminal Sortasetag. A post-translational one-pot reaction was used to fuse a CoA-647 fluorescent dye to the NTermini via an Sfp-catalyzed reaction. In parallel, the eSortase fuses a GG-sfGFP towards the Cterminal LPETGG. (B) An image of a SDS gel obtained following dual labeling of ELPs under different reaction conditions and ELP lengths. The image shows only the red CoA-647 dye (ex: 530/28, em: $695 / 55 \mathrm{~nm}$ ). (C) Fluorescent image of the same gel as in B, but this time with blue excitation (ex: 470/530, em: 530/28 nm), hence only the native GFP specific bands are visible. (D) Overlay of B and C plus additional UV illumination which excites tryptophan side group converted fluorophores enabled by the Bio-Rad Stain-Free ${ }^{\mathrm{TM}}$ technology.

Figure 3. Cloud point characterization of the $10-60$ pentapeptide ELP repeats

(A) shows the characteristic decrease in the transition temperature of the ELPs with increasing sodium chloride concentration and ELP length. (B) illustrates the relation between increasing transition temperature and decreasing molecular weight. (C) shows the correlation between $\mathrm{pH}$, $\mathrm{NaCl}$ and transition temperature. (D) shows the concentration dependency of the transition temperature for the 60 pentapeptide ELP repeat. Data points for the plots were obtained from triplicates. Error bars represent the standard deviation of the average transition point.

Figure 4. Cloning schematic and bioconjugation of cysteine-ELPs with a maleimide-dye and PEG-maleimide.

(A) Illustration of the cloning schematic for changing the ELP flanking regions (i.e. replacement of the ybbR-sequence with a cysteine). The ybbR-sequence was deleted via a PCR reaction, and a cysteine was introduced (see Primers 10 and 11 in Table 1). The flanking restriction sites were digested with $B s a \mathrm{I}-\mathrm{HF}$ and the remaining sticky ends were filled in with Klenow Fragment. Finally, the linear product was circularized with T4 ligase. (B) Procedure of the bioconjugation reaction. Cysteine-ELPs were reduced with TCEP and conjugated to a maleimide dye or a PEGmaleimide polymer. A gel image on the right shows the successful conjugation reaction between the dye and the ELP. (C) Bioconjugation of a $20 \mathrm{kDa}$ PEG-maleimide to CYS-ELP 60 shifted the cloud point up by $\sim 4^{\circ} \mathrm{C}$ (left panel). The cloud point of $\mathrm{ELP}_{60}$ lacking cysteine (middle panel) was not influenced by the addition of maleimide PEG. The right panel shows the cloud point shift $(\Delta \mathrm{T})$ due to addition of different concentrations of PEG-maleimide. Data points for the plot were obtained from triplicates. Error bars account for Gaussian error propagation due to calculation of the difference of the average transition point from three samples. 
1

2

3

4

5

6

7

8

9

10

11

12

13

14

15

16

17

18

19

20

21

22

23

24

590

586 For Table of Contents Use Only

587 Sequence Independent Cloning and Post-translational Modification of Repetitive Protein

588 Polymers through Sortase and Sfp-mediated Enzymatic Ligation

589 Wolfgang Ott, Thomas Nicolaus, Hermann E. Gaub and Michael A. Nash

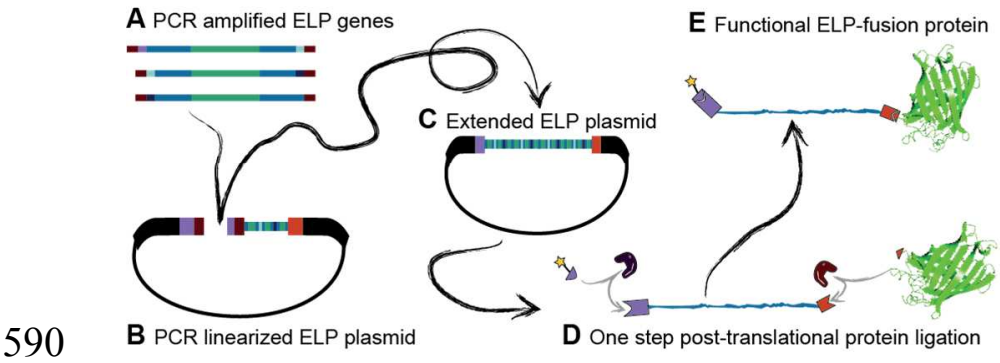


A Primers and starting material

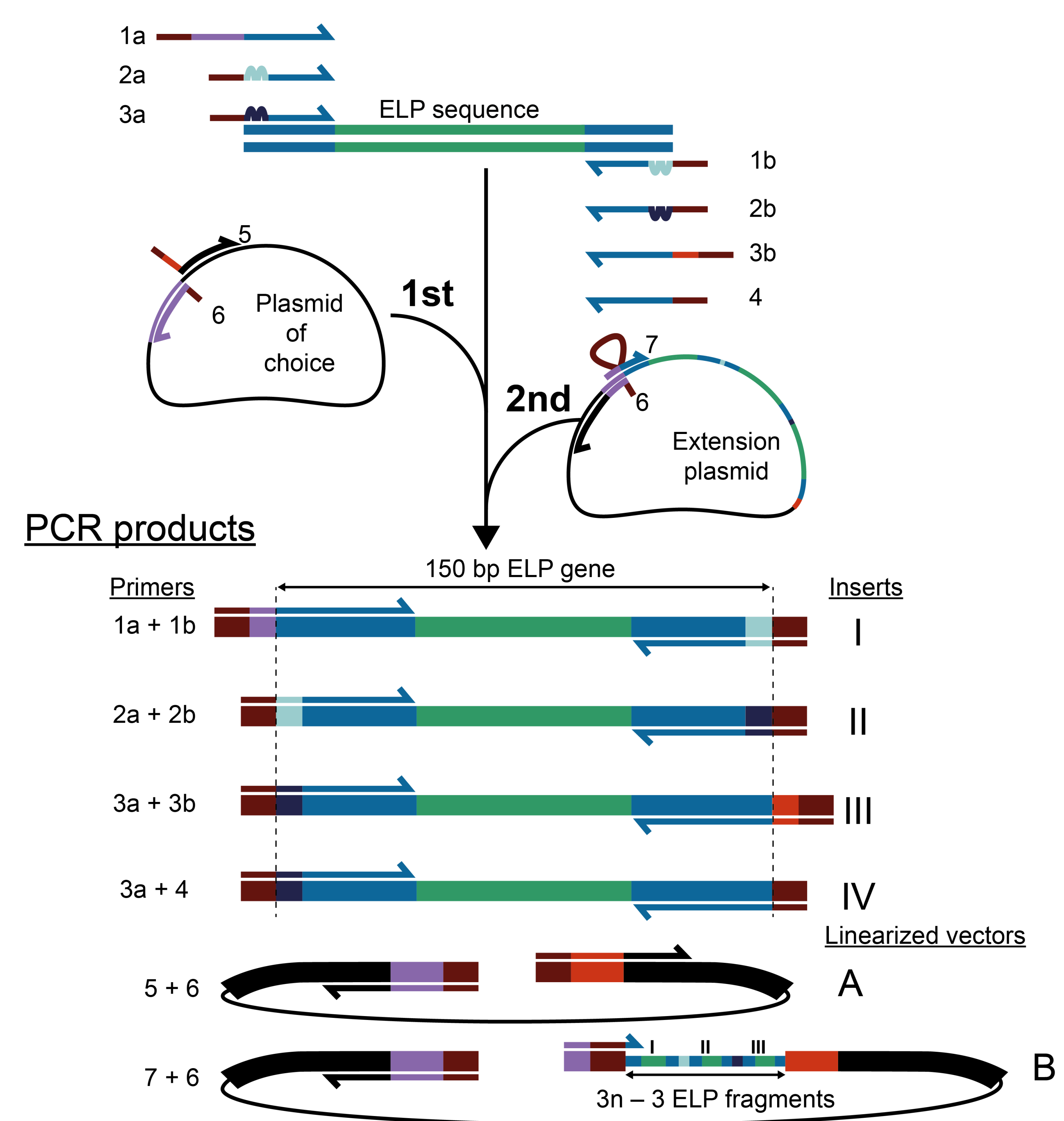

\begin{tabular}{|c|c|c|c|c|c|}
\hline ELP & ELP (codon shuffled) & ybbR-tag & Sortase c-tag & Bsal restriction site & $\begin{array}{l}\mathrm{n} \text { : number of } \\
\text { cloning rounds }\end{array}$ \\
\hline
\end{tabular}

\section{B ${ }^{\text {sio }}$ Cepononining}

1st round

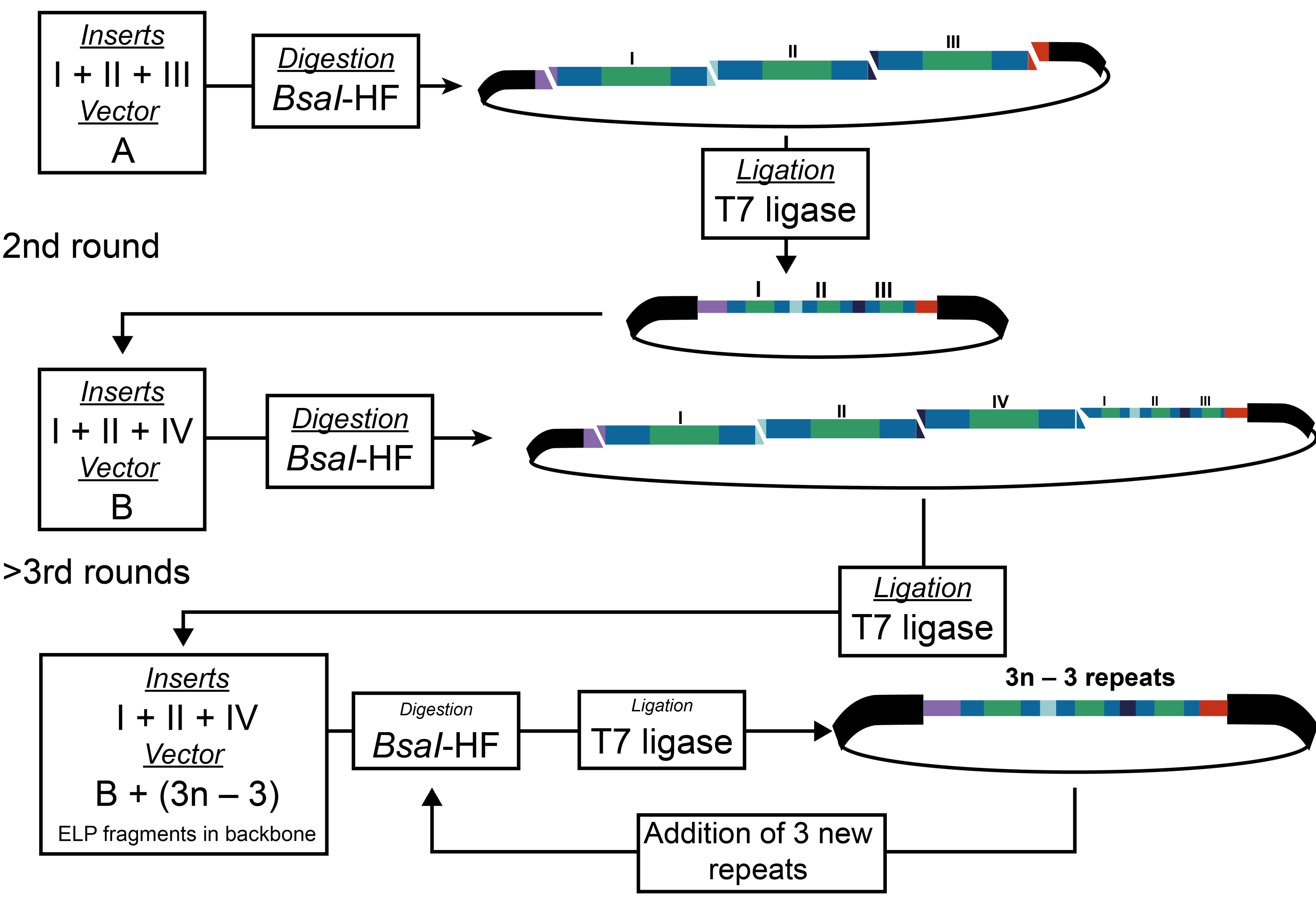

$\begin{array}{llllllllll}1 x & 2 x & 3 x & 4 x & 5 x & 6 x & 7 x & 8 x & 9 x & 12 x\end{array}$

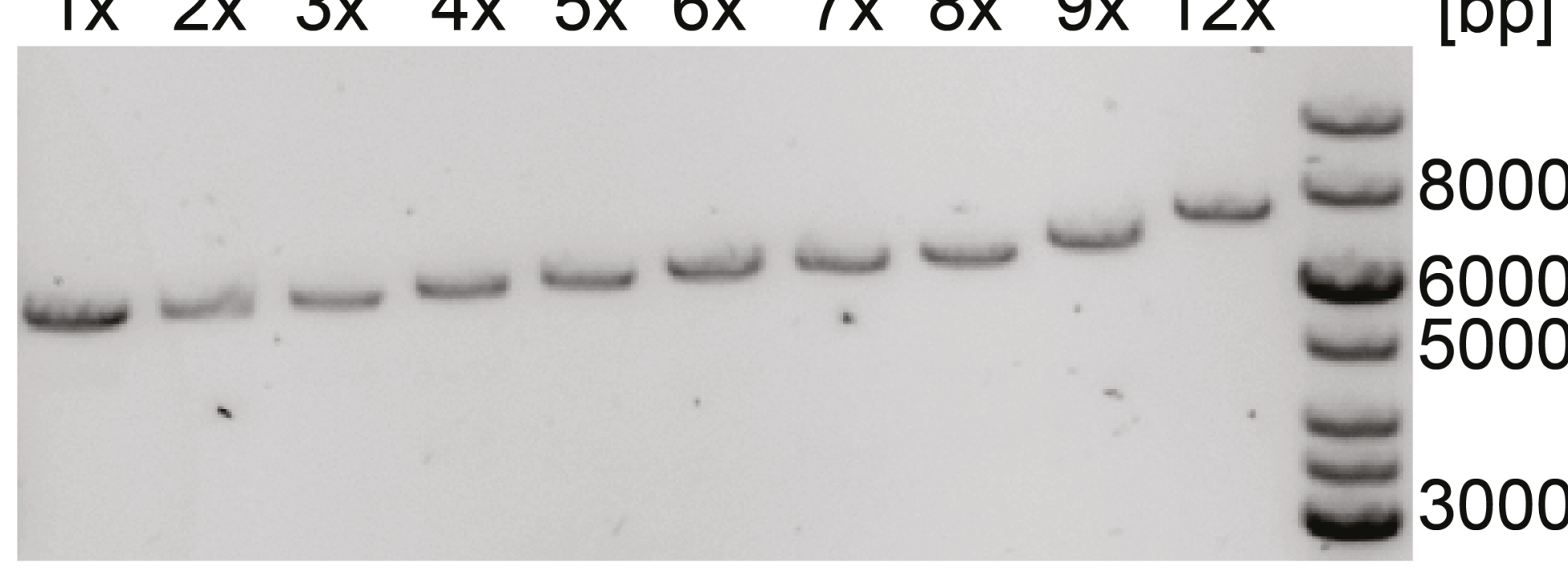


ybbR tag

零

CoA-Dye

LPETGG

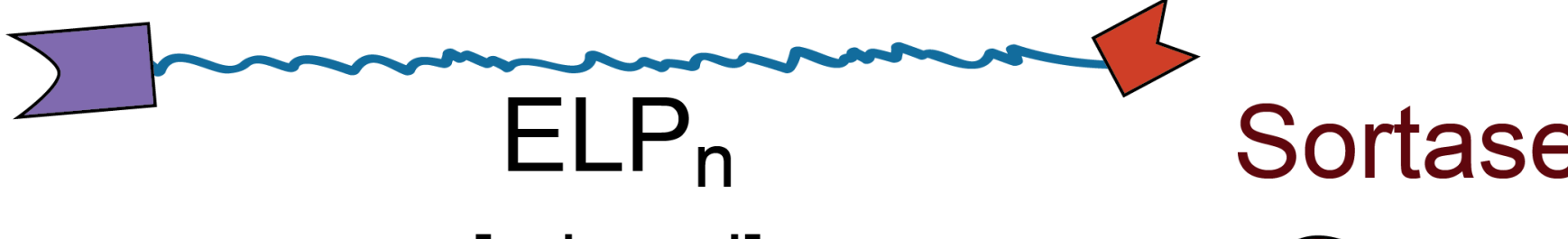

[relaxed]

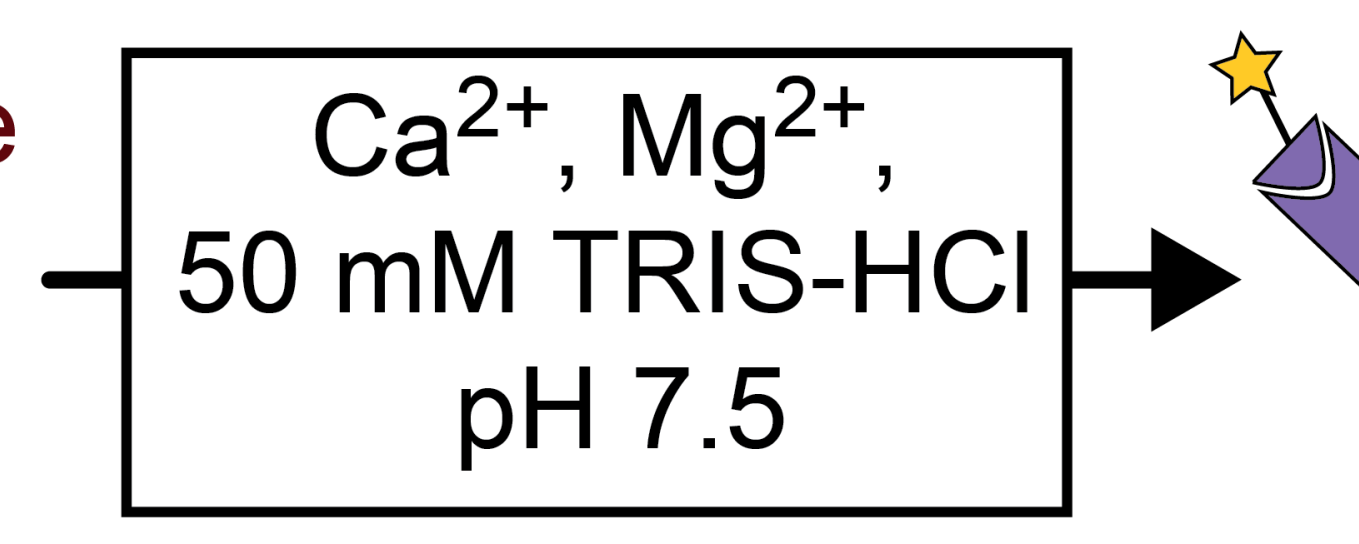

Sfp

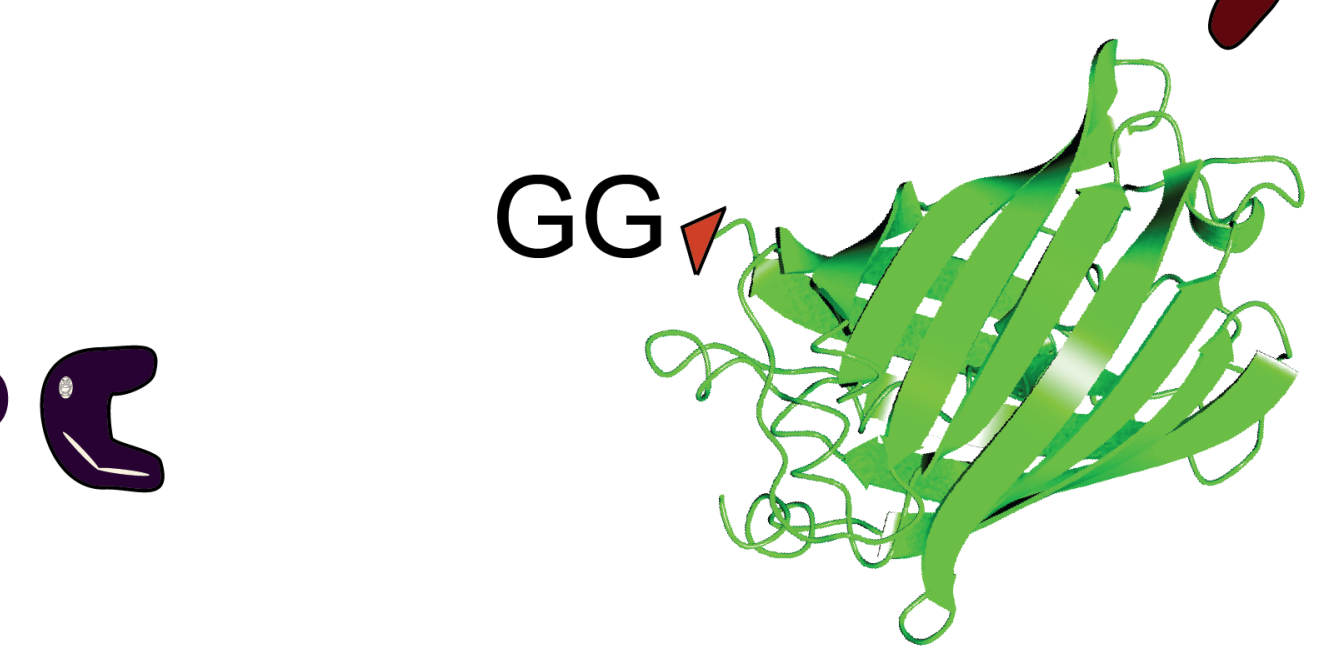

$\mathrm{pH} 7.5$

Dye Fluorescence 530/28 - 695/55 nm

C GFP Fluorescence 470/30-530/28 nm

D Overlay: Panel B (red), Panel C (green)

$\operatorname{ELP}_{20} \mathrm{ELP}_{30} \quad \mathrm{ELP}_{40} \mathrm{ELP}_{50} \mathrm{ELP}_{60}$

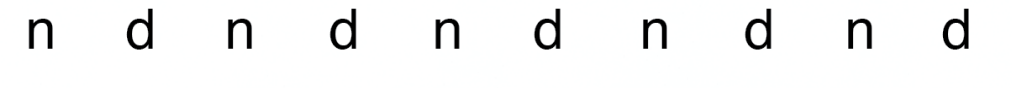

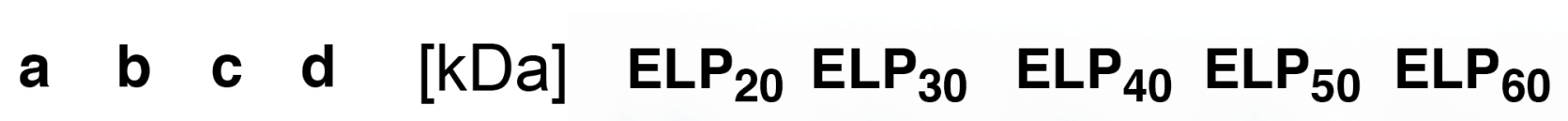

$\begin{array}{lllllllllll}100 & n & d & n & d & n & d & n & d & n & d\end{array}$

a $\quad$ b $\quad c$ d $[\mathrm{kDa}]$

$\mathrm{ELP}_{20} \mathrm{ELP}_{30} \mathrm{ELP}_{40} \mathrm{ELP}_{50} \mathrm{ELP}_{60}$

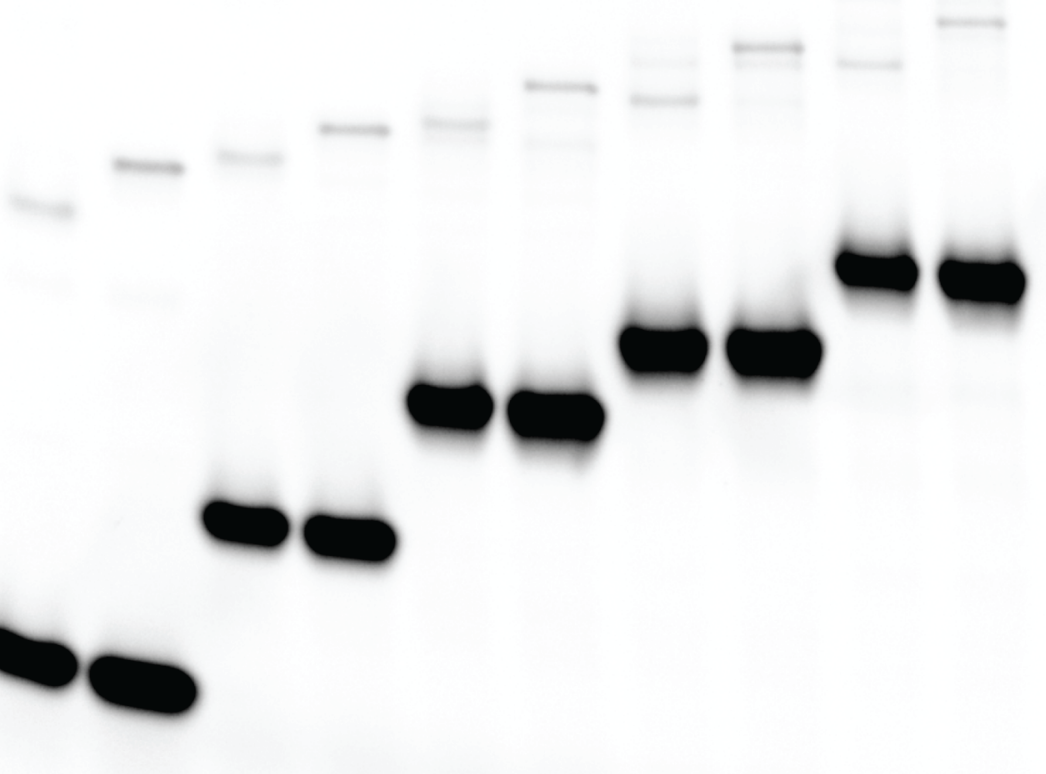

$50---$

37

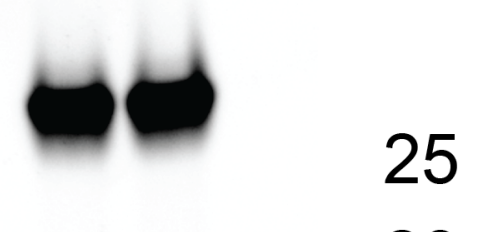

20

15

ELP $_{20-60}: 20$ - 60x Pentapeptide-Repeat n: native d: denaturated

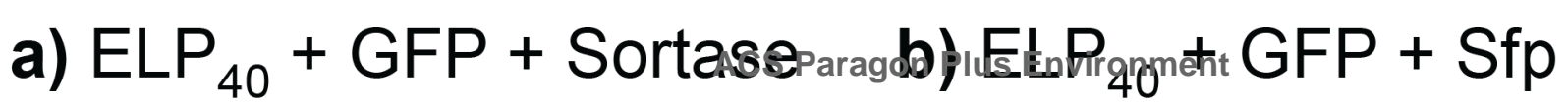

c) $\mathrm{ELP}_{40}+\mathrm{Sfp}+$ Sortase d) GFP + Sfp + Sortase

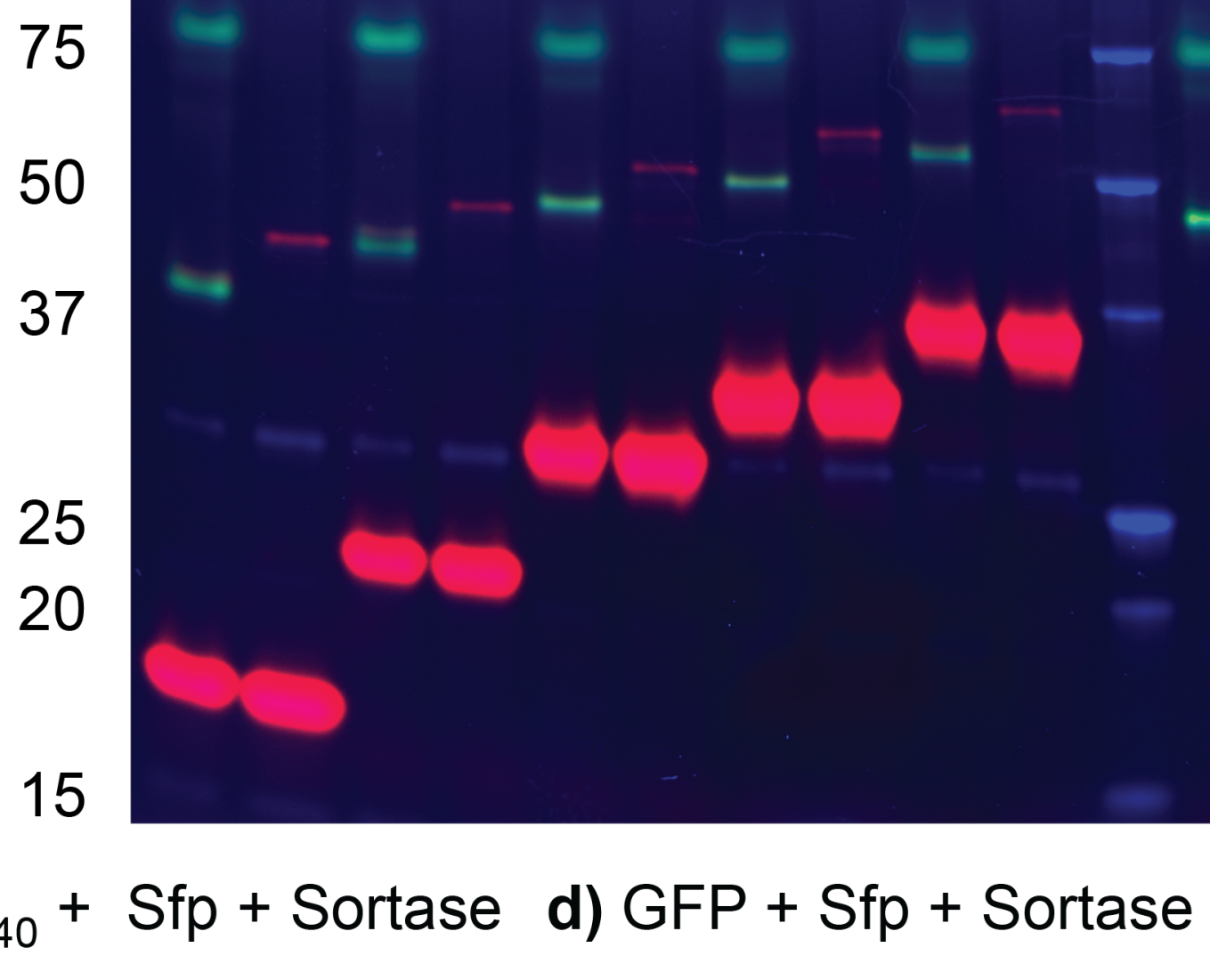




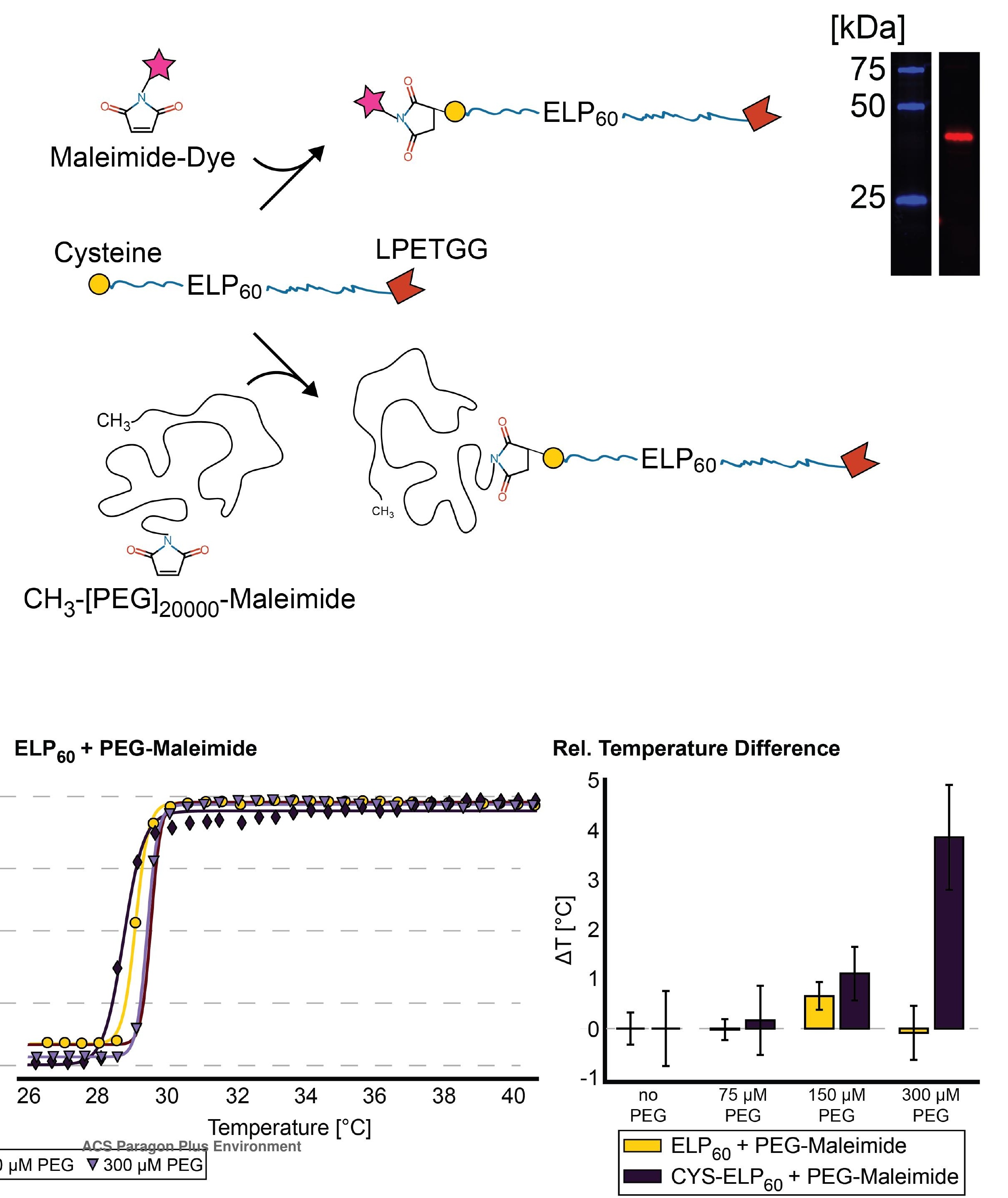

